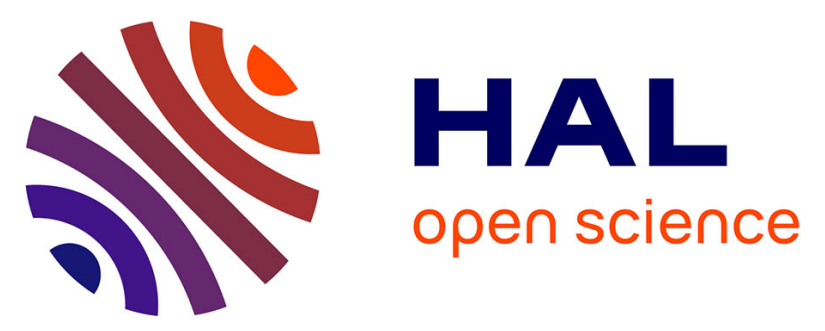

\title{
TMF-LCF life assessment of a Lost Foam Casting A319 aluminum alloy
}

Shadan Tabibian, Eric Charkaluk, Andrei Constantinescu, Fabien Szmytka, Alexis Oudin

\section{- To cite this version:}

Shadan Tabibian, Eric Charkaluk, Andrei Constantinescu, Fabien Szmytka, Alexis Oudin. TMF-LCF life assessment of a Lost Foam Casting A319 aluminum alloy. International Journal of Fatigue, 2012, 10.1016/j.ijfatigue.2012.01.012 . hal-00757313

\section{HAL Id: hal-00757313 \\ https://hal-polytechnique.archives-ouvertes.fr/hal-00757313}

Submitted on 19 Feb 2020

HAL is a multi-disciplinary open access archive for the deposit and dissemination of scientific research documents, whether they are published or not. The documents may come from teaching and research institutions in France or abroad, or from public or private research centers.
L'archive ouverte pluridisciplinaire HAL, est destinée au dépôt et à la diffusion de documents scientifiques de niveau recherche, publiés ou non, émanant des établissements d'enseignement et de recherche français ou étrangers, des laboratoires publics ou privés.

\section{(c)(1)}

Distributed under a Creative Commons Attribution| 4.0 International License 


\title{
TMF-LCF life assessment of a Lost Foam Casting A319 aluminum alloy
}

\author{
Shadan Tabibian ${ }^{\mathrm{a}, \mathrm{b}, \mathrm{c}}$, Eric Charkaluk ${ }^{\mathrm{b}, *}$, Andrei Constantinescu ${ }^{\mathrm{c}}$, Fabien Szmytka ${ }^{\mathrm{a}}$, Alexis Oudin ${ }^{\mathrm{a}}$ \\ ${ }^{a}$ Automotive Research and Innovation Division, PSA Peugeot Citroën, Route de Gisy, 78943 Vélizy-Villacoublay, France \\ ${ }^{\mathrm{b}}$ LML, Laboratoire de Mécanique de Lille, CNRS UMR 8107, Ecole Centrale de Lille-Cité Scientifique, 59650 Villeneuve d'Ascq, France \\ ${ }^{\mathrm{c}}$ LMS, Laboratoire de Mécanique des Solides, CNRS UMR 7649, Ecole Polytechnique, Route de Saclay, 91120 Palaiseau, France
}

The LFC (Lost Foam Casting) process affects the microstructure, the mechanical properties, the damage mechanisms and the fatigue failure of the materials. The first purpose of this paper is to study the cyclic mechanical behaviors, damage and lifetime of the A319 aluminum alloy manufactured by the LFC process used in the automotive industry under TMF (Thermo-Mechanical Fatigue) and LCF (Low Cycle Fatigue) conditions. A second objective is to select an effective fatigue criterion which should be easy to apply for the design of structures submitted to complex multiaxial thermo-mechan-ical loadings. In this way, several energy-based criteria are used to predict fatigue failure. Good agree-ment between predicted fatigue lifetimes and experimental results was obtained for different TMF and LCF loading conditions.

\section{Introduction}

Engine efficiency, specific power increase and engine size reduction transformed the Thermo-Mechanical Fatigue (TMF) of the cylinder head fire deck into a critical design aspect in the automotive industry [1-4]. Therefore, the durability assessment of these components is increasingly in demand to ensure field reliability targets [5,6]. Automotive power train applications, except the exhaust system, are characterized by low to intermediate operating temperatures up to $300^{\circ} \mathrm{C}$. Therefore, the silicon $(\mathrm{Si})$, magnesium $(\mathrm{Mg})$ and copper $(\mathrm{Cu})$ based aluminum alloys used in the cylinder head component are exposed to operating temperatures higher than those of their final heat treatment. These operating temperatures potentially induce creep and aging effects and need to be considered in durability assessment [7].

The excellent castability and mechanical properties of the A319 alloy make it a popular choice in automotive applications. Its low specific gravity mass is essential to reduce energy consumption, and its excellent corrosion resistance and the low cost of recycling are also important considerations from an environmental point of view. Addition of $\mathrm{Cu}$ to eutectic Al-Si alloys leads to a slight increase in alloy fluidity, and a reduction of the Si eutectic temperature of $1.8^{\circ} \mathrm{C}$ for every $1 \mathrm{wt} . \% \mathrm{Cu}$ added. Also, some of the mechanical properties obviously benefit from the addition of $\mathrm{Cu}$

* Corresponding author at: LML, Laboratoire de Mécanique de Lille, CNRS UMR 8107, Ecole Centrale de Lille-Cité Scientifique, 59650 Villeneuve d'Ascq, France. E-mail address: eric.charkaluk@ec-lille.fr (E. Charkaluk). as an alloying element such as yield strength and ultimate tensile strength $[8,9]$.

Recently Lost Foam Casting (LFC) replaced Die Casting (DC) as a standard casting process. The main drawbacks of the LFC process are the coarsening of the microstructure in terms of DAS (Dendrite Arm Spacing) or grain size, essentially due to low solidification rates, residual porosity, and brittle phases (eutectics, intermetallics) formed during the degradation of the polymeric pattern $[10,11]$. Previous investigations have shown that, besides the grain size and the grain boundary, other important metallurgy factors that significantly affect the ductile fracture of aluminum alloys are the second-phase particles inherently contained in the alloys, including large $\mathrm{Fe}-, \mathrm{Cu}-, \mathrm{Mg}-$ and Si-rich inclusions (about $110 \mu \mathrm{m}$ in diameter), intermediate $\mathrm{Cr}$-, $\mathrm{Mn}$ - or $\mathrm{Zr}$-rich dispersoids and small precipitates (nanometer size). The large particles, defined as constituents, are brittle in nature, have different elastic and thermal properties and are usually the primary void/crack initiators or the preferential crack propagation path. As a result, the influence of the constituents on the ductile fracture of aluminum alloys has attracted extensive attention in the recent literature [12].

This paper presents first a series of LCF and TMF tests performed to investigate the influences of over aging and fatigue loading on the cyclic mechanical properties, fatigue lifetime, and damage mechanisms of the A319 aluminum alloy obtained by the LFC process. In a second step, in order to compare their prediction capability, a number of energy-based fatigue criteria coming from literature $[13,16,17]$ are proposed and the TMF experimental and computed results are discussed. 
Table 1

Nominal chemical composition of A319.

\begin{tabular}{|c|c|c|c|c|c|c|c|c|c|c|c|c|}
\hline Material & $\mathrm{Si}(\%)$ & Mn (\%) & $\mathrm{Fe}(\%)$ & $\operatorname{Mg}(\%)$ & $\mathrm{Cu}(\%)$ & $\mathrm{Zn}(\%)$ & $\mathrm{Ti}(\%)$ & $\mathrm{Ni}(\%)$ & $\mathrm{Sr}(\mathrm{ppm})$ & $\mathrm{P}(\mathrm{ppm})$ & V (\%) & $\mathrm{Zr}(\%)$ \\
\hline A319 & 7.18 & 0.15 & 0.43 & 0.32 & 3.17 & 0.19 & 0.05 & 0.010 & 0.020 & 0.010 & 0.006 & 0.002 \\
\hline
\end{tabular}

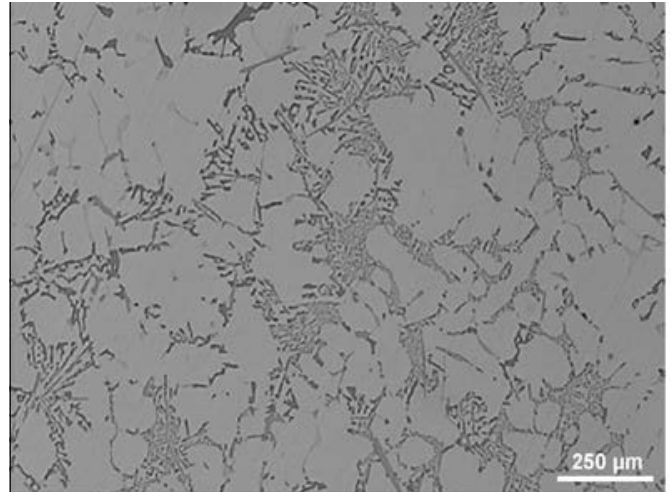

(a)

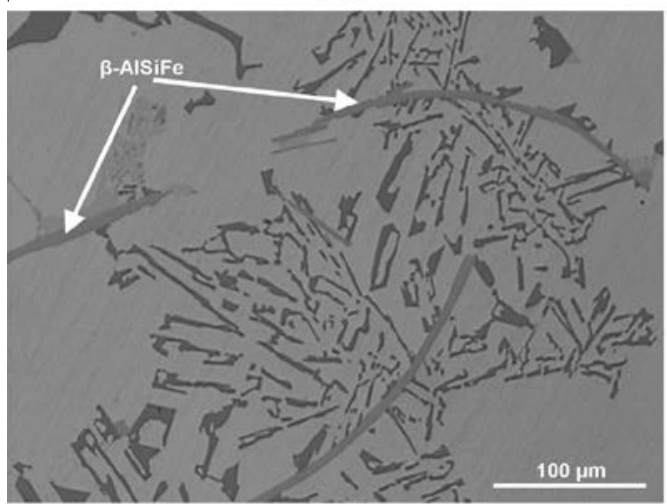

(c)

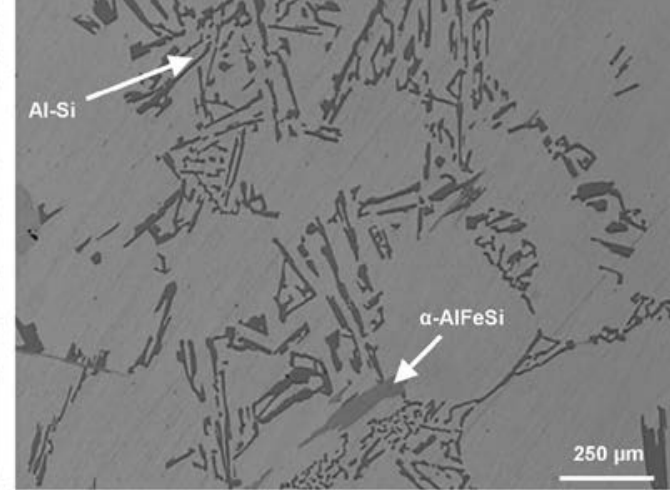

(b)

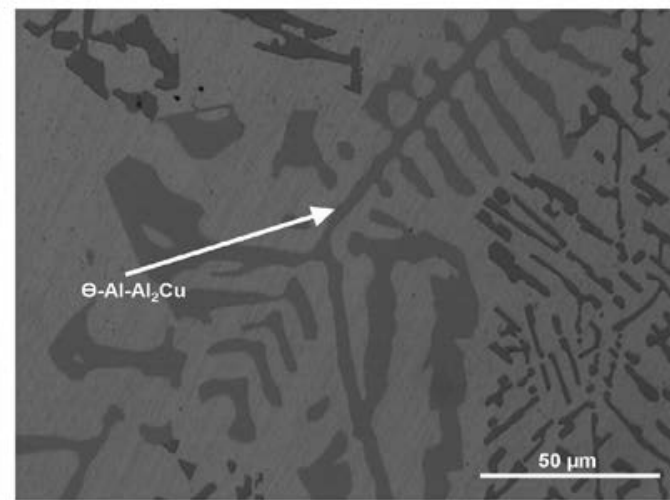

(d)

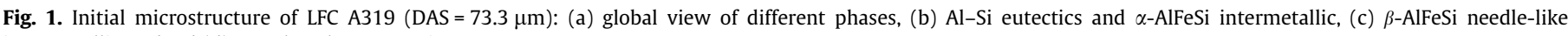
intermetallics, ad=nd (d) $\theta-\mathrm{Al}-\mathrm{Al}_{2} \mathrm{Cu}$ eutectics.

\section{Experiments}

\subsection{Materials and composition}

The alloy studied here is a A319 aluminum-silicon alloy obtained by the LFC process and with no heat treatment, as applied to the automotive industry. An overview of its chemical composition is presented in Table 1 . The specimens were extracted from the inter-valve zones of industrially manufactured cylinder heads in order to obtain the same microstructure as on components, i.e. a DAS of $73.7 \mu \mathrm{m}$ was measured for the A319 alloy after microstructural observations. Two material states will be compared next, the initial state with no heat treatment and the over aged state obtained after aging the material for $200 \mathrm{~h}$ at $250{ }^{\circ} \mathrm{C}$.

SEM (Scanning Electron Microscopy) observations were carried out and, as displayed in Fig. 1, the microstructure presents two pre-eutectic iron-based intermetallics, $\alpha$-AlFeSi and $\beta$-AlFe$\mathrm{Si}$, and a copper-based eutectic $\left(\theta-\mathrm{Al}-\mathrm{Al}_{2} \mathrm{Cu}\right)$. Similar observations were made previously for example in [18]. It will further be shown that these different phases play an important role in the fatigue damage process.

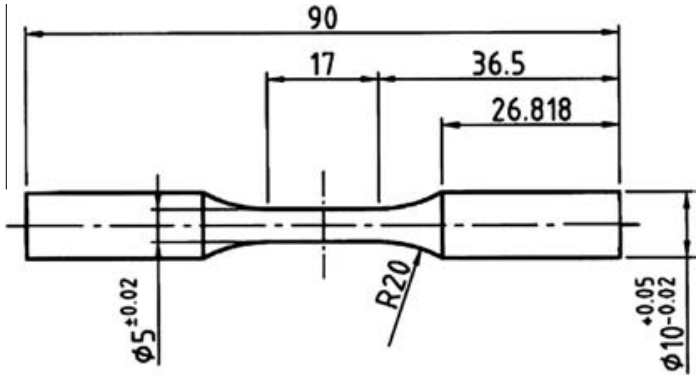

Fig. 2. Geometry of the cylindrical specimen used for LCF and TMF tests.

\subsection{Experimental procedures}

This study was based on strain-controlled TMF and LCF tests $[6,19]$. A servohydraulic machine was used to perform the fatigue tests on a cylindrical plain specimen (see Fig. 2). Two separate induction coils were used for the heating. LCF tests were carried out at $150{ }^{\circ} \mathrm{C}, 200{ }^{\circ} \mathrm{C}$ and $250^{\circ} \mathrm{C}$ for variable mechanical strain ranges $(\Delta \epsilon=0.1-0.8 \%)$. The results of the LCF tests for the A319 alloy are presented and compared to the A356 in [20] where several energy-based fatigue criteria are discussed. 
Table 2

Summary of tests condition for LCF = Low Cycle Fatigue and TMF = Thermo-Mechanical Fatigue.

\begin{tabular}{llll}
\hline Test & Dwell time & $T\left({ }^{\circ} \mathrm{C}\right)$ & $\Delta \epsilon(\%)$ \\
\hline LCF & 0 & 250 & $0.1-0.8$ \\
LCF & 0 & 200 & $0.1-0.5$ \\
LCF & 0 & 150 & $0.1-0.3$ \\
TMF & 0 & $100-250$ & $0.2-0.6$ \\
TMF & $50 \mathrm{~s}$ at $T_{\max }$ & $100-250$ & 0.4 \\
TMF & $50 \mathrm{~s}$ at $T_{\max }$ and $T_{\min }$ & $100-250$ & 0.4 \\
\hline
\end{tabular}

The TMF tests are out-of-phase tests with or without dwell time at maximum or minimum temperatures. The maximum mechanical strain ranges were $\Delta \epsilon=0.2-0.6 \%$, with a mechanical strain ratio $R_{\epsilon}=-1$ and a strain rate $\dot{\epsilon}=10^{-3}(1 / \mathrm{s})$. Maximum and minimum temperatures are $250{ }^{\circ} \mathrm{C}$ and $100^{\circ} \mathrm{C}$ respectively and the chosen temperature range is close to the engines in-service start-stop temperature ranges. The dwell time at maximum or minimum temperature was $50 \mathrm{~s}$. Constant heating and cooling rates are applied (linear variations of temperature with time), depending on the applied strain range. Blowing-air and watercooled grip systems were then used to cool down the specimens from $250{ }^{\circ} \mathrm{C}$ to $100^{\circ} \mathrm{C}$. Longitudinal gradients were initially controlled so that there was less than $5^{\circ} \mathrm{C}$ between the upper or lower side of the specimen and its center.

The loading conditions of the different tests are displayed in Table 2 . The testing conditions were applied to both non-aged and over aged A319 alloys.
Table 3

TMF tests on aged A319, with or without dwell time.

\begin{tabular}{cllc}
\hline Specimen & Dwell time & $\Delta \epsilon \%$ & $N_{f}(10 \%$ stress drop $)$ \\
\hline 1 & 0 & 0.6 & 71 \\
2 & 0 & 0.5 & 195 \\
3 & 0 & 0.2 & 2034 \\
4 & 0 & 0.6 & 226 \\
5 & 0 & 0.2 & 4134 \\
6 & 0 & 0.6 & 220 \\
7 & 0 & 0.4 & 943 \\
8 & 0 & 0.4 & 328 \\
9 & 0 & 0.4 & 445 \\
10 & 0 & 0.4 & 349 \\
11 & 50 s at $T_{\max }$ & 0.4 & 429 \\
12 & 50 s at $T_{\max }$ & 0.4 & 325 \\
13 & 50 s at $T_{\max }$ and $T_{\min }$ & 0.4 & 142 \\
14 & 50 s at $T_{\max }$ and $T_{\min }$ & 0.4 & 303 \\
\hline
\end{tabular}

\section{Experimental results and discussion}

\subsection{Cyclic behavior and lifetimes}

The cyclic mechanical behaviors under TMF-LCF conditions for the aged and non-aged A319 alloy are presented in Fig. 3.

The left panels in Fig. 3a and c present the maximum normalized induced stress versus the number of cycles, while the right panels of Fig. $3 \mathrm{~b}$ and d display the stabilized hysteresis loop in terms of axial strain and normalized axial stress. This hysteresis loop is defined as the strain-stress cyclic behavior of the material for a cycle in which maximum stress is almost stabilized at the

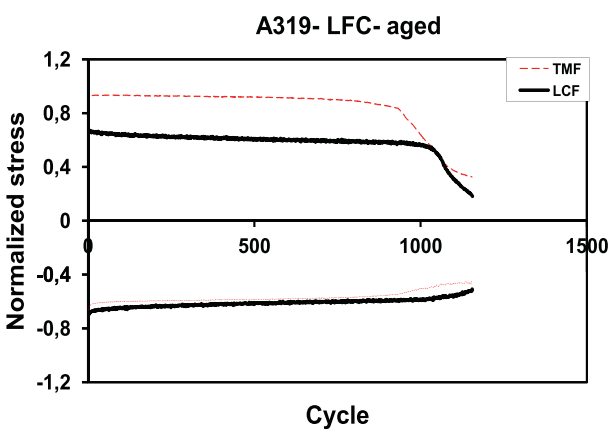

(a)

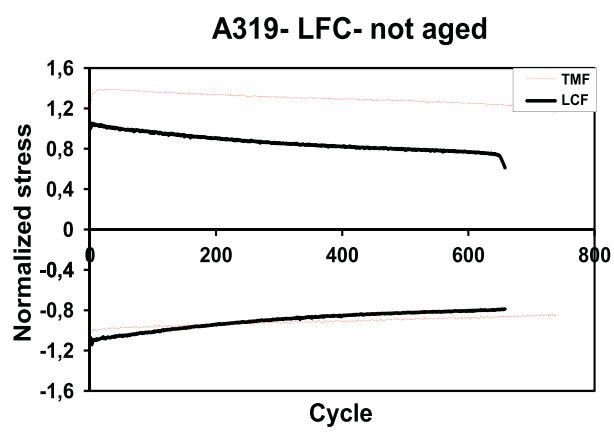

(c)

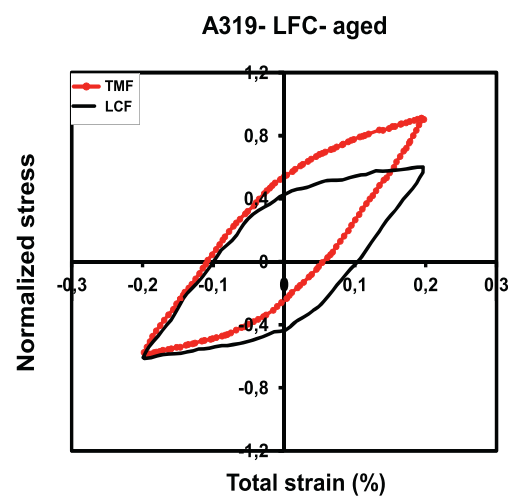

(b)

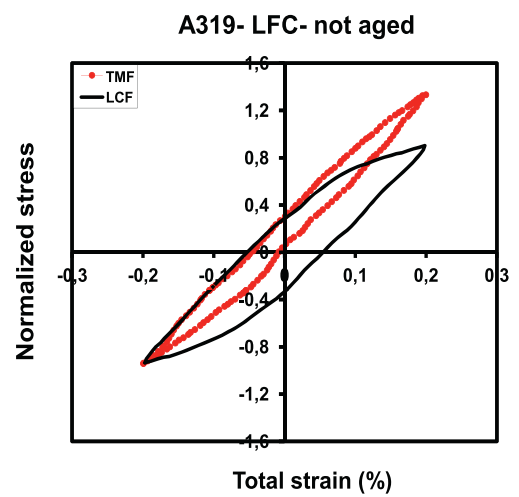

(d)

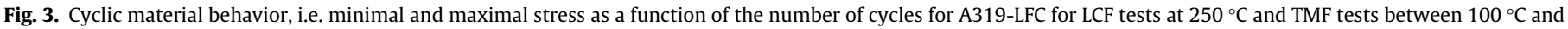
$250{ }^{\circ} \mathrm{C}$ : (a) in over aged condition, (b) in non-aged condition; corresponding hysteresis strain-stress loops, (c) in over aged condition, and (d) in non-aged condition. 


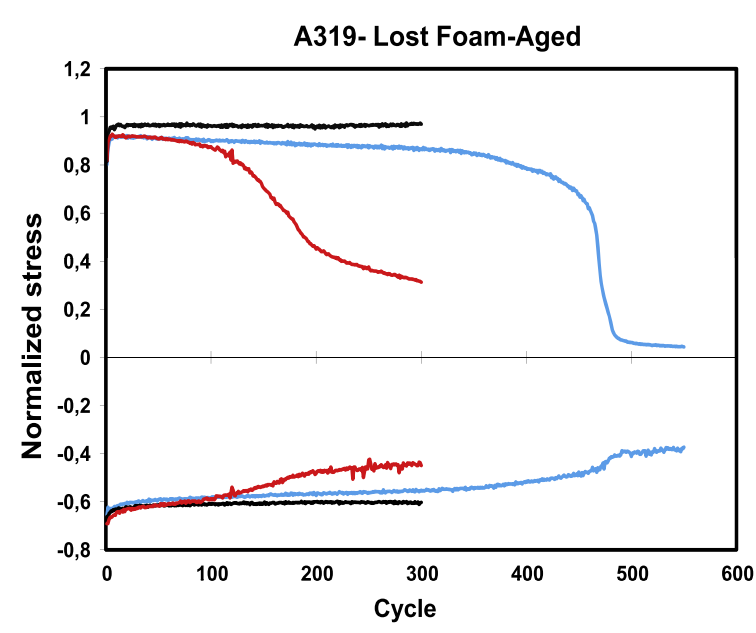

(a)

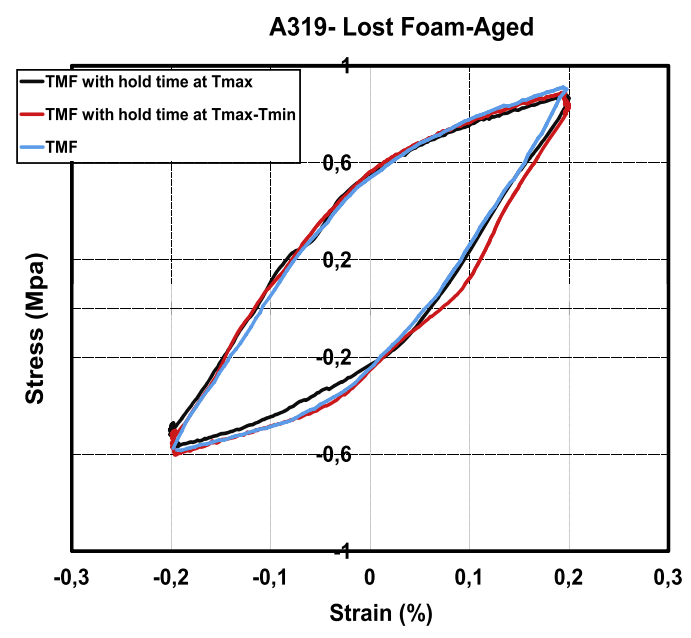

(b)

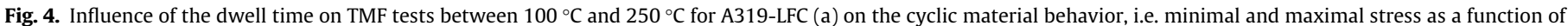
the number of cycles (b) and on the corresponding hysteresis strain-stress loops

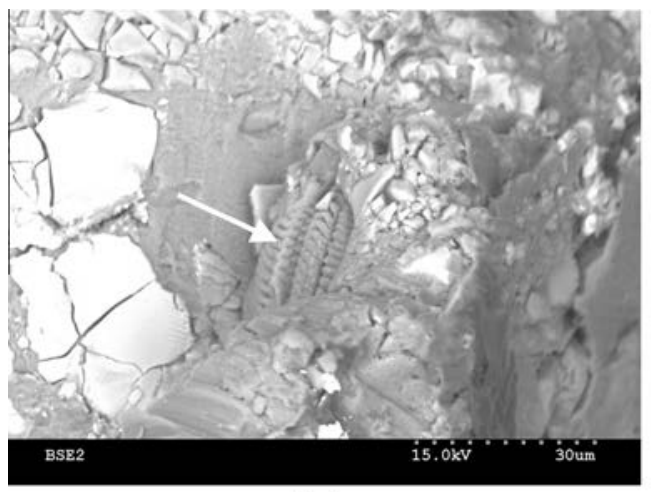

(a)

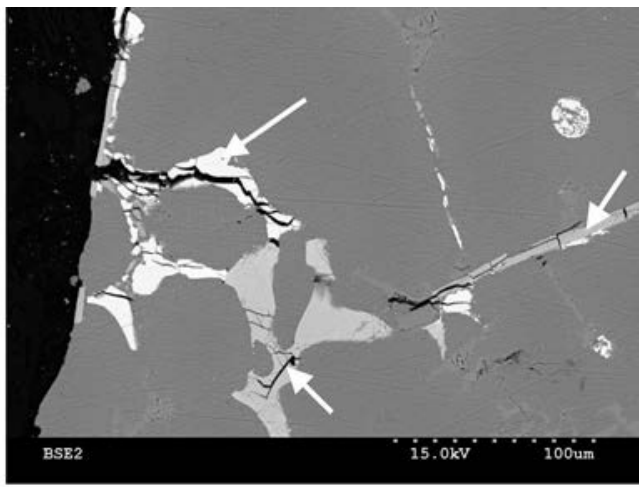

(b)

Fig. 5. Tire tracks and fragile rupture after LCF tests at $250^{\circ} \mathrm{C}, \Delta \epsilon=0.8 \%$ (a) tire tracks and (b) micro-cracks inside intermetallic and eutectic phases.

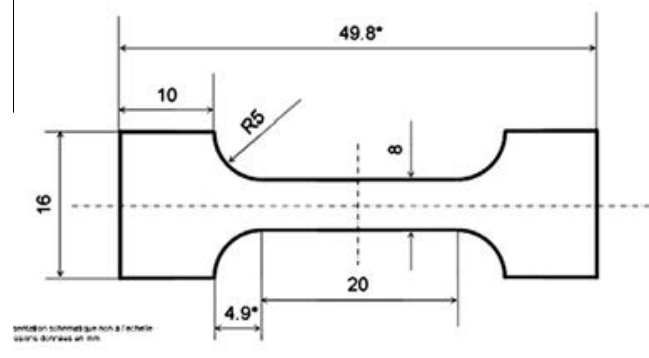

(a)

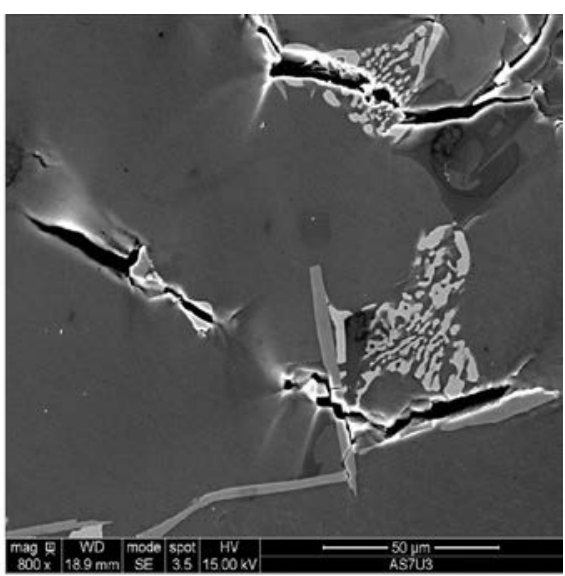

(b)

Fig. 6. In situ tensile test at room temperature, $\Delta \epsilon=0.45 \%$ (a) specimen geometry and (b) crack path following brittle eutectic/intermetallic phases.

transition between the high and low softening domains. In all cases, the axial stresses are normalized by the maximum stress value obtained in the first cycle of the LCF test in the non-aged con- dition presented in Fig. $3 c$ and d. However, the "normalized maximum stress" will simply be denoted by the "maximum stress" in the following. 
Fatigue lifetime is classicaly defined as a 10\% stress drop compared to the stabilized stress, so before the complete fracture of the specimen. We can therefore note that the final fracture of the specimen occurs after $110-120 \% N_{f}$ cycles. This additional lifetime corresponds to a macroscopic crack growth.

If we compare the cyclic behavior of the aged and non-aged specimens in Fig. 3, one can observe a larger hysteresis loop in the aged condition and also smaller minimum and maximum stresses. This is the case for both TMF and LCF tests. One can also note that for these cases lifetimes seem to be inferior for non-aged materials. Moreover, the left panels in Fig. 3a and c exhibit a more pronounced softening for non-aged specimens, for both TMF and LCF tests, compared to aged specimens. This is due to the cumulative effect of the cyclic loading and the ageing process which occur during the tests because of the high temperatures. One can then note that softening is more pronounced during the LCF tests. In fact, the material in LCF tests is subjected to a high temperature $\left(250^{\circ} \mathrm{C}\right)$ during the whole cycle, up to failure, contrary to the TMF loadings in which the material is under high temperature $\left(250^{\circ} \mathrm{C}\right)$ for a short period of time. As the coarsening of the precipitation occurs at higher temperatures [21] the softening of the material will be amplified during LCF loading. This leads to a greater decrease in the maximum and minimum stress and a wider hysteresis loop during the LCF tests compared to TMF.

Moreover, it should also be noted that, as TMF tests are conducted between low and high temperatures, the maximum stress obtained in the TMF tests is higher than in the LCF tests, as it corresponds to $100{ }^{\circ} \mathrm{C}$ and $250^{\circ} \mathrm{C}$ respectively. Therefore, the positive mean stress obtained during the TMF tests is higher than that observed in the LCF tests, which is close to zero.

Finally, the TMF lifetime of different specimens with or without dwell time are compared in Table 3. These tests are conducted with or without dwell time at maximum and minimum temperatures. Fig. 4 shows that the fatigue lifetime of LFC A319 is significantly reduced by dwell time at maximum and minimum temperatures, although the hysteresis strain-stress loops remain nearly identical.

\subsection{Damage mechanisms}

Post mortem damage observations were finally carried out on fracture surfaces using a SEM. Panels (a) and (b) in Fig. 5 represent the LFC A319 alloy under LCF loading conditions at $250{ }^{\circ} \mathrm{C}$ with the strain amplitude ( $\Delta \epsilon=0.8 \%$ ). A large number of micro-cracks is observed both on the boundaries and inside the eutectic phases. A concentration of micro-cracks was observed inside the intermetallic phases $\beta$-AlFeSi and the eutectic $\theta-\mathrm{Al}-\mathrm{Al}_{2} \mathrm{Cu}$ phases.

Fractures exhibited relatively smooth areas with distinct periodic markings (Fig. 5a) generally denoted as tire tracks. These markings are produced by particles being successively impressed on the mating surfaces of the crack during the crack closure period of the loading cycle [22].

The observations made before and after the testing (see Figs. 1 and 5 , respectively) did not permit to detect the initiation moment of the micro-cracks or the initial position of the dominant crack. Post mortem observations of the fracture surfaces seem to reveal that the initiation of the first micro-cracks generally occurred in the neighborhood of the $\beta$-AlFeSi interemetallic phases and propagated toward the micro-porosities. In order to validate this observation, in situ tensile tests were performed in a SEM with an applied axial strain close to $0.45 \%$ at room temperature. The observations of the sample confirm that the crack in the phases occurs in the first loading steps of the sample and coalesce later toward a macroscopic crack (see Fig. 6). The crack initiation within the intermetallic phases can certainly be explained by the stress and strain concentration in the phases and at their boundaries due to a gap in mechanical properties. This sudden rupture mechanism has already been observed and described in [23].

\section{Fatigue lifetime assessment}

As it has been observed, under TMF conditions, crack initiation seems to caused by a fracture of intermetallics in the aluminum matrix. Consequently, the crack growth mainly occurs along brittle phases in the eutectic structure (see Fig. 5b).

Also underlined is the effect of aging and cyclic loading on the induced hysteresis loop and on the mean stress value. Even if the cumulated cyclic plastic strain on a cycle is a first-order parameter in the LCF/TMF process in such aluminum alloys, because of coupling between plasticity and damage, the mean stress effects can be assumed to be considerable on the A319 alloy since damage seems to occur quickly in intermetallics. It therefore seems advantageous to test different LCF criteria based on these mechanical parameters.

The damage induced in the material due to the cyclic loading, described in the previous section, can be estimated using the classical criterion based on dissipated energy denoted as $W$ [24-26].

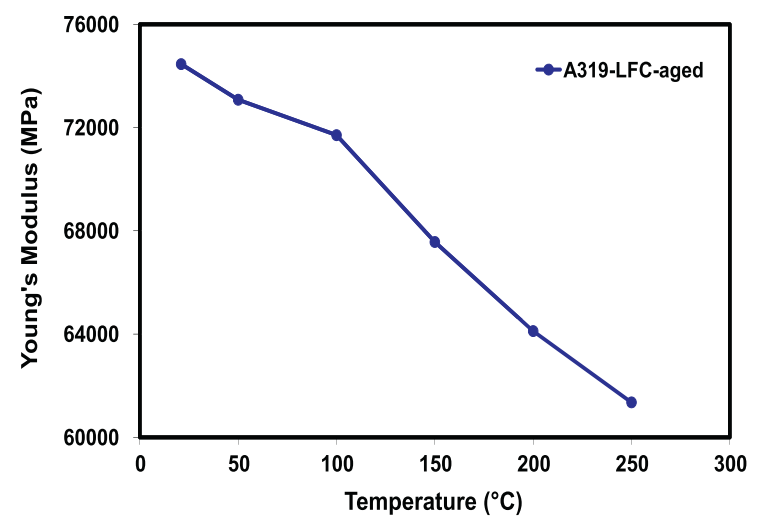

Fig. 7. Evolution of the Young's modulus $E$ as a function of temperature for the aged LFC A319.

Table 4

$\alpha, c, d, e$, and $f$ parameters estimation by linear regression from LCF test results for A319.

\begin{tabular}{lllll}
\hline$\alpha$ & $c$ & $d$ & $e$ & $f$ \\
\hline 0.0055 & 2.64 & 2.16 & 3.32 & -1.87 \\
\hline
\end{tabular}

Table 5

Power law parameter estimation by linear regression from LCF test results for A319 and $R^{2}$ parameter.

\begin{tabular}{llll}
\hline Criterion & $\mathrm{A}$ & $\mathrm{B}$ & $R^{2}$ LCF \\
\hline$W$ & 8.4 & -0.57 & 0.87 \\
$W_{\sigma_{H}}$ & 4.14 & -0.37 & 0.93 \\
$W_{\sigma_{e} f f}$ & 8.7 & -0.44 & 0.89 \\
\hline
\end{tabular}

Table 6

$R^{2}$ parameter for A319 under TMF conditions.

\begin{tabular}{ll}
\hline Criterion & $R^{2} \mathrm{TMF}$ \\
\hline$W$ & 0.89 \\
$W_{\sigma_{H}}$ & 0.9 \\
$W_{\sigma_{e} f f}$ & 0.89 \\
\hline
\end{tabular}


However, as this criterion cannot render the role of the mean stress effect, other criteria are tested in this paper: the $W_{\sigma_{H}}$ criterion [13-15] with a fatigue parameter combining plastic dissipated energy and a term based on the maximum hydrostatic stress max $\sigma_{H}$, and the $W_{\sigma^{\text {eff }}}$ criterion [17] with a fatigue parameter combining plastic dissipated energy and a term based on effective stress $\sigma_{\text {eff. }}$

For the sake of simplicity, we will now denote $\phi_{i}$ the fatigue parameter, which corresponds to each of these criteria. The index $i$ will denote the additional terms in the expression of the fatigue parameter that are introduced in order to take into account hydrostatic, mean stress effects, etc. The fatigue lifetime of the material is then calculated via a standard power law:

$\phi_{i}=A\left(N_{f}\right)^{B}$

where $N_{f}$ is the lifetime (number of cycles to failure), and $A$ and $B$ are two real material parameters that were identified by linear regression from the LCF test results (not presented here) and then used in the actual TMF life prediction. The fatigue parameter $\phi_{i}$ was calculated from the stabilized cycles (see Fig. 3). In the following criteria, the stress amplitude, maximum stress, minimum stress, and hydrostatic pressure are read directly from the measured stabilized hysteresis curve, while the plastic dissipated energy is calculated by integrating over the cycle:

$W=\int_{\text {cycle }} \sigma \cdot \dot{\epsilon_{p}} d t$

where $\sigma$ is the axial stress and $\dot{\epsilon}_{p}$ the axial plastic strain rate. Therefore, in the case of the dissipated energy, $\phi=W$. In the $W_{\sigma^{\text {eff }}}$ criterion, the effective stress amplitude is defined as in [17] by:

$\Delta \sigma_{\text {eff }}=\Delta \sigma \cdot e \cdot(3-R)^{f} \quad R=\frac{\sigma_{\min }}{\sigma_{\max }}$

and the fatigue parameter is:

$\phi_{\sigma^{\text {eff }}}=d W+c \frac{\left(\Delta \sigma_{\text {eff }}\right)^{2}}{2 E}$

where $W$ corresponds to the dissipated energy and is calculated by using Eq. (2), and $c, d, e$, and $f$ are some material parameters. Moreover, it can be noted that the difficulty when applying the $\phi_{\sigma^{e f f}}$ criterion for TMF loadings is to determine which elastic modulus $E$ should be used in the computation [27]. For the aluminum alloy studied, a variation of $200{ }^{\circ} \mathrm{C}$ in temperature implied a variation of approximatively $15 \%$ of the Young modulus (see Fig. 7). Consequently, the modulus in our computations is defined as the mean value of the Young modulus at maximum and minimum temperatures of TMF loadings.

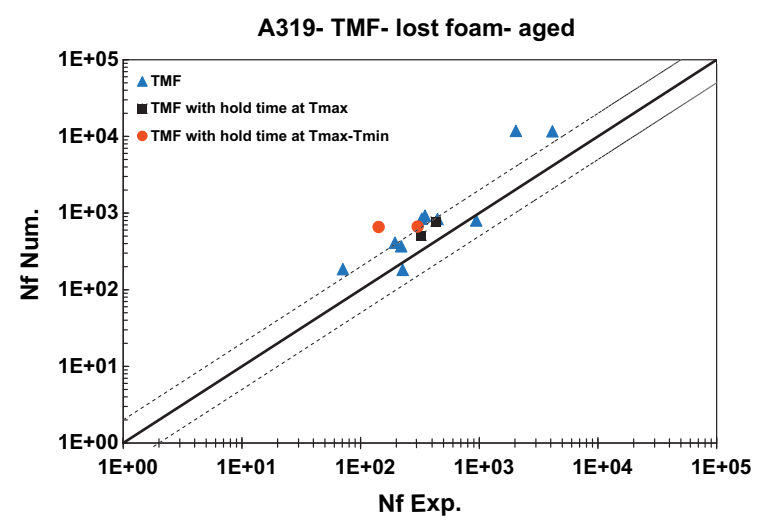

(a)
The last energy-based criterion proposed in this study is $\phi_{\sigma_{H}}$ and its complete expression is:

$\phi_{\sigma_{H}}=W+\alpha \sigma_{H}^{\max } \quad \sigma_{H}^{\max }=\max _{\text {cycle }} \frac{1}{3} \operatorname{tr}(\sigma)$

where $W$ corresponds to the dissipated energy calculated by using Eq. (2), $\sigma_{H}^{\max }$ is the maximal hydrostatic pressure during the stabilized cycle, and $\alpha$ is a material parameter.

Then, in addition to the parameters $(A, B)$ of the power law Eq. 1, there is only one parameter to identify $\alpha$ in $\phi_{\sigma_{H}}$ compared to the four parameters $c, d, e$, and $f$ of the $\phi_{\sigma_{e} f f}$ criterion. As previously stated, all parameters are then calculated by linear regression and optimization of the LCF test results by minimizing a least-square function between measured and estimated lifetimes [13]. These parameters are then used in TMF life prediction. The parameters $\alpha, c, d, e$, and $f$ are presented in Table 4 and $(A, B)$ of the power law equation are presented in Table 5 .

In order to compare the prediction capabilities of the different criteria accurately, we propose to use the correlation coefficient $R^{2}$, corresponding to the linear association between experimental fatigue lifetimes and computed fatigue lifetimes. $R^{2}$ is defined as in standard statistical textbooks as:

$R^{2}=\frac{\sum_{j=1}\left(N_{j}^{\text {exp }}-\bar{N}\right)\left(\phi_{j}^{\text {exp }}-\bar{\phi}\right)}{\sum_{j=1}\left(N_{j}^{\text {comp }}-\bar{N}\right)^{2} \sum_{j=1}\left(\phi_{j}^{\text {comp }}-\bar{\phi}\right)^{2}}$

where $N_{i}$ and $\phi_{j}$ are the lifetimes and fatigue parameters of the experiment $i$ and the subscripts ${ }^{\exp }$ and ${ }^{\operatorname{comp}}$ stand for the experimental and the computed values of $\Phi$ respectively. One can note, that the $R^{2}$ defined is exactly the coefficient of linear regression between experimental fatigue lifetimes and damage functions. The computed correlation coefficients for each criterion are given in Table 6 and the results obtained with the different criteria are presented in Figs. 8a and $b$ and 9.

In these figures, the predicted and experimental lifetimes obtained with aged LFC-A319 alloy under TMF conditions are compared. One can first observe that lifetimes obtained for TMF tests without dwell time are quite well predicted by the different criteria but, in this particular case, $\phi_{W_{\sigma_{H}}}$ criterion seems to give the better results as all the points are very close to a \pm 2 factor on the lifetimes. One can note also that the lifetimes obtained for TMF tests with dwell time at $T_{\max }$ are also well predicted. However, in all cases, lifetimes for TMF tests with dwell time at $T_{\min }$ and $T_{\max }$ are overestimated. This is certainly due to the unfavorable effect of dwell time in tension as previously pointed out for many materials [6]. If we compare the $R^{2}$ obtained for the different criteria,

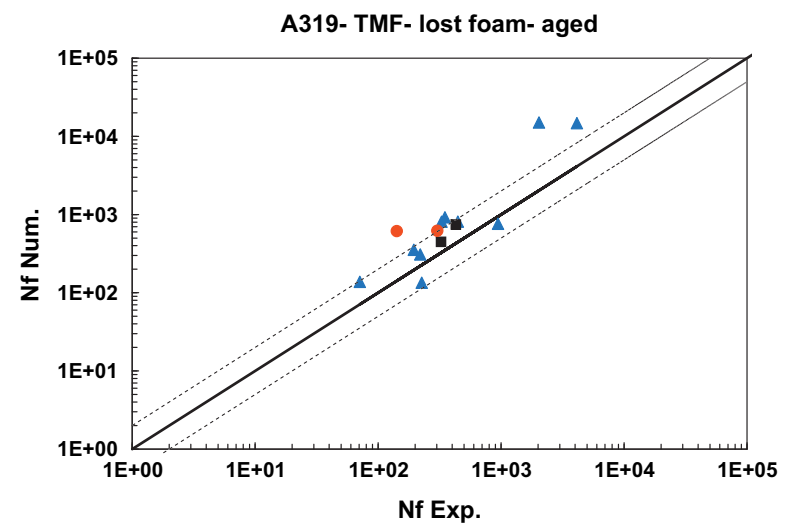

(b)

Fig. 8. Experimental TMF life versus predicted fatigue life: (a) $W$ criterion for A319-LFC and (b) $W_{\sigma}^{\text {eff }}$ criterion for A319-LFC. 


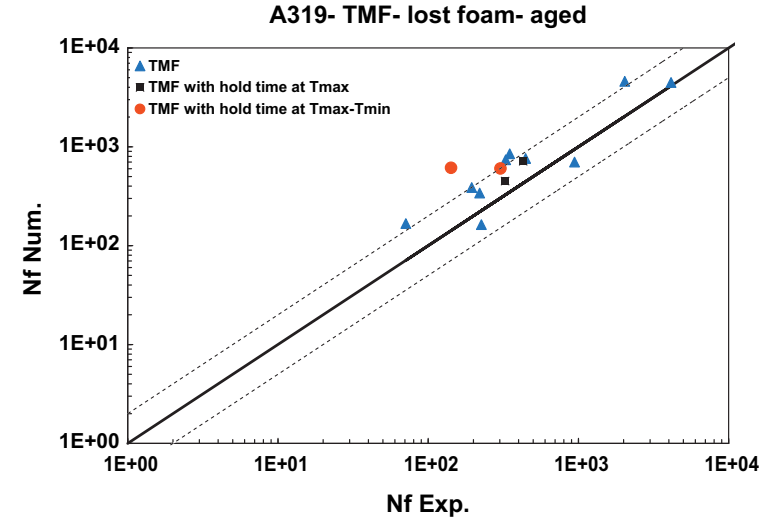

Fig. 9. Experimental TMF life versus predicted fatigue life: $\sigma_{H}^{\max }$ criterion for A319LFC.

one can note that all the energy-based criteria are relatively equivalent for the lifetime prediction even if $\phi_{W_{\sigma_{H}}}$ best fits the predicted lifetime results with the experimental results.

\section{Conclusion}

The purpose of this paper was to study the mechanical properties, damage mechanisms, and the fatigue lifetime of the $\mathrm{A} 319$ aluminum alloy used in cylinder heads coming from Lost Foam Casting process. The SEM observations showed the high density of the intermetallics and eutectic phases in the initial microstructure of LFC A319. LCFTMF test results revealed the different cyclic mechanical properties and fatigue failures of the material: A319 alloy exhibits a higher yield stress in TMF tests compared to LCF tests. In addition, in non-aged conditions A319 alloy exhibits higher yield stress compared to the over aged condition. A higher fatigue lifetime was estimated for A319 in LCF tests compared to TMF tests.

The post mortem SEM observation of A319 in the LFC process was carried out, showing a severe brittle fracture inside the eutectic phases and iron-based intermetallics; several tire tracks were observed which proves the damage of a particle or a set of particles.

Finally, different thermo-mechanical fatigue failure energybased criteria were defined to predict the fatigue lifetime of the A319 LFC material. The material-dependent parameters of these criteria were extracted from the LCF tests. It was shown that all these energy-based criteria present a good agreement between the experimental fatigue lifetime results and the computed results and that the results are relatively improved when incorporating the hydrostatic pressure in an energy approach.

\section{Acknowledgments}

The authors thank David Balloy, Jean-Yves Dauphin and JeanCharles Tissier at the Ecole Centrale de Lille, France, for their help in SEM analysis and fruitful discussion during this study. The authors also thank Veronique Doquet, Daniel Caldemaison and Eva Heripre from LMS (Laboratoire de Mécanique des Solides) for the in situ tests.
The authors would like also to thank the reviewers for very interesting remarks which allow to improve the precision of the paper.

This study was supported by PSA Peugeot-Citroen and received the financial support of the French Minister of Science, which are both gratefully acknowledged.

\section{References}

[1] Nagayoshi T, Kodaira T. Analysis of thermal fatigue cracks in cylinder heads. JSAE Rev 1993;14(2):56-60.

[2] Smith T, Maier H, Sehitoglu H, Fleury E, Allison J. Modelling high-temperature stress-strain behavior of cast aluminum alloys. Metal Mater Trans A 1999;30:133-46.

[3] Thomas JJ, Verger L, Bignonnet A, Charkaluk E. Thermomechanical design in the automotive industry. Fatigue Fract Eng Mater Struct 2004;27:887-95.

[4] Fischersworring-Bunk A, Thalmair S, Eibl M, Kunst M, Dietsche A. High temperature fatigue and creep automotive power train application perspectives. Mater Sci Technol 2007;23:1389-95.

[5] Sehitoglu H. Thermal and thermomechanical fatigue of structural alloys. ASM Handbook 1996;19:527-56.

[6] Remy L. Thermal-mechanical fatigue (including thermal shock). Comprehen Struct Integr 2003;5:113-99.

[7] Yuan SP, Liu G, Wang RH, Zhang G-J, Pu X, Sun J, et al. Aging-dependent coupling effect of multiple precipitates on the ductile fracture of heat-treatable aluminum alloys. Mater Sci Eng A 2009;499:387395.

[8] Hatch JE. Aluminum: properties and physical metallurgy. Metals Park $(\mathrm{OH})$ : American Society for Metals; 1984.

[9] Moustafa MA, Samuel FH, Doty HW, Valtierra S. Effect of solution heat treatment additives on the microstructure of Al-Si A413.1 automotive alloys. Int J Cast Metals Res 2002;14:235.

[10] Gupta M, Lavernia EJ. Effect of processing on the microstructural variation and heat-treatment response of a hypercutectic Al-Si alloy. J Mater Process Technol 1995;261:54.

[11] Campbell J. The concept of net shape for castings. Mater Des 2000;21:373.

[12] Zhang GJ, Wang RH, Yuan SP, Liu G, Scudino S, Sun J, et al. Influence of constituents on the ductile fracture of AlCuMg alloys: modulated by the aging treatment. Mater Sci Eng 2009;526:171-6.

[13] Amiable S, Chapuliot S, Constantinescu A, Fissolo A. A comparison of lifetime prediction methods for a thermal fatigue experiment. Int $\mathrm{J}$ Fatigue 2006;28:692-706.

[14] Amiable S, Chapuliot S, Constantinescu A, Fissolo A. A computational lifetime prediction for a thermal shock experiment. Part I: Thermomechanical modeling and lifetime prediction. Fatigue Fract Eng Mater Struct 2006;29(3):209-17.

[15] Amiable S, Chapuliot S, Constantinescu A, Fissolo A. A computational lifetime prediction for a thermal shock experiment. Part II: discussion on different fatigue criteria. Fatigue Fract Eng Mater Struct 2006;29(3):219-27.

[16] Koh SK. Fatigue damage evaluation of a high pressure tube steel using cyclic strain energy density. Int J Press Vessels Piping 2002;79:791-8.

[17] Heitmann HH, Vehoff H, Neumann P. Life prediction for random load fatigue based on the gro behaviour of microcracks. Pergamon Press Ltd.; 1984.

[18] Backerud L, Chai G, Tamminen J. Solidification characteristics of aluminum alloys. In Foundy alloys. Stockholm (Sweden): AFS/Skan Aluminum; 1990.

[19] Charkaluk E, Rémy L. Fatigue of materials and structures: application to damage and design, vol. 2. Wiley-ISTE; 2010 [chapter Thermal fatigue] ISBN:978-1-84821-267-1.

[20] Tabibian S, Charkaluk E, Constantinescu A,Szmytka F, Oudin A. TMF criteria for lost foam casting aluminum alloys. Fat Fract Engg Mat Struct, submitted for publication.

[21] Nicouleau-Bourles E. Etude expérimentale et numérique du vieillissement d'un alliage d'aluminium. Application aux culasses automobiles. PhD thesis. Ecole Nationale Supérieure des Mines de Paris; 1999 [French thesis].

[22] Borrego LP, Abreu LM, Costa JM, Ferreira JM. Analysis of low cycle fatigue in AlMgSi aluminium alloys. Eng Failure Anal 2004;11:715-25.

[23] Ran G, Zhou JE, Wang QG. Precipitates and tensile fracture mechanism in a sand cast A356 aluminum alloy. J Mater Process Technol 2008;207:46-52.

[24] Feltner CE, Morrow JD. Micro-plastic strain hysteresis energy a criterion for fatigue fracture. Trans ASME 1961.

[25] Morrow J. Cyclic plastic strain energy and fatigue of metals, in Internal Friction Damping and Cyclic Plasticity, STP 378, ASTM, 1965. p. 45-87.

[26] Dowling NE. Fatigue failure predictions for complicated stress-stain histories. J Mater 1972;7:71-87.

[27] Charkaluk E, Constantinescu A. An energetic approach in thermomechanical fatigue for silicon molybdenum cast iron. Mater High Temp 2000;3:373-80. 